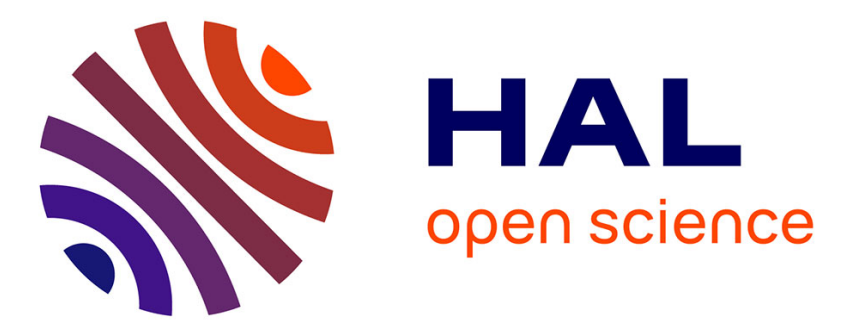

\title{
Moldable multispectral glasses in GeS2-Ga2S3-CsCl system transparent from the visible up to the thermal infrared regions
}

Antoine Bréhault, Laurent Calvez, Philippe Adam, Joel Rollin, Michel Cathelinaud, Bo Fan, Odile Merdrignac-Conanec, Thierry Pain, Xiang-Hua Zhang

\section{To cite this version:}

Antoine Bréhault, Laurent Calvez, Philippe Adam, Joel Rollin, Michel Cathelinaud, et al.. Moldable multispectral glasses in GeS2-Ga2S3-CsCl system transparent from the visible up to the thermal infrared regions. Journal of Non-Crystalline Solids, 2016, 431, pp.25-30. 10.1016/j.jnoncrysol.2015.04.016 . hal-01145804

\author{
HAL Id: hal-01145804 \\ https://hal.science/hal-01145804
}

Submitted on 31 Aug 2015

HAL is a multi-disciplinary open access archive for the deposit and dissemination of scientific research documents, whether they are published or not. The documents may come from teaching and research institutions in France or abroad, or from public or private research centers.
L'archive ouverte pluridisciplinaire HAL, est destinée au dépôt et à la diffusion de documents scientifiques de niveau recherche, publiés ou non, émanant des établissements d'enseignement et de recherche français ou étrangers, des laboratoires publics ou privés. 


\title{
Moldable multispectral glasses in $\mathrm{GeS}_{2}-\mathrm{Ga}_{2} \mathrm{~S}_{3}-\mathrm{CsCl}$ system transparent from the visible up to the thermal infrared regions
}

\author{
Antoine Bréhault ${ }^{1}$,Laurent Calvez, 1 Philippe Adam², Joel Rollin ${ }^{3}$, Michel \\ Cathelinaud ${ }^{1}$, Bo Fan ${ }^{1}$, Odile Merdrignac-Conanec ${ }^{1}$, Thierry Pain ${ }^{l}$ and Xiang- \\ Hua Zhang ${ }^{l}$
}

${ }^{1}$ Laboratoire Verres et Céramiques, UMR 6226, Institut des Sciences Chimiques de Rennes, Université de Rennes 1, 35042 Rennes Cedex, France

${ }^{2}$ DGA/DS - Mission pour la Recherche et l'Innovation Scientifique, 7 rue des Mathurins, 92221

Bagneux, France

${ }^{3}$ Thalès Angénieux, 42570 Saint-Héant, France

\section{Contact :}

Address : Laboratoire Verres et Céramiques, UMR 6226, Institut des Sciences Chimiques de Rennes, Université de Rennes 1, 35042 Rennes Cedex, France.

E-mail: xzhang@univ-rennes1.fr

\section{Introduction}

During the recent years, there has been a strong growth of thermal imaging market, mainly thanks to the development of uncooled focal plane detector arrays [1]-[3]. This market evolution has boosted the development of infrared transmitting glasses as more economical solution for infrared optics, compared with the generally used germanium and $\mathrm{ZnSe}$. Molded chalcogenide glass optical components are now commercially available and the most recent studies are focused on the improvement of mechanical properties or far infrared transmission [4]-[8].

Among all commercialized chalcogenide optics, no one shows enough transmission in the visible region. However, there is an increasing demand for simultaneous imaging in the two highly complementary spectral domains which are the visible/SWIR (short wavelength infrared, $0.9-1.7 \mu \mathrm{m}$ ) region and the thermal infrared region $(8-12 \mu \mathrm{m})$. These multispectral materials would able the fusion of three images simultaneously on a screen and afford a better vision of the space to the users. It will lead to many new applications both in commercial and defense fields. As an example, for car driving assistance, visible/SWIR image is better for reading road indications and for detecting the presence of ice on the road. Thermal image is much better for seeing further and observe pedestrians in foggy condition and during the night. For defense applications, it is, for example, easier to move in the dark with intensified SWIR image and thermal imaging is indispensable to detect hidden hot target.

There are many optical components operating either in the visible/SWIR region or in the far infrared region. Only two materials, known since long time, $\mathrm{ZnS}$ and $\mathrm{ZnSe}$, can be considered for the production of multispectral optics even they cover only partially these two spectral bands [9]. These materials are manufactured through a long and expensive chemical vapor deposition (CVD). They are polycrystalline materials and consequently, no molded optic is possible. The only way to produce complex asphero-diffractive optics, indispensable with these materials, is to use the expensive single point diamond turning. 
Among chalcogenide glasses, sulfide glasses possess the largest transmission in the visible range with an infrared transmission up to 11-12 $\mu \mathrm{m}$. In order to increase the transmission in the visible region, alkaline halides are generally introduced into the chalcogenide glasses. The most studied glass-forming system is certainly the $\mathrm{GeS}_{2}-\mathrm{Ga}_{2} \mathrm{~S}_{3}-\mathrm{CsCl}$ system in which more than $50 \mathrm{~mol} \%$ of $\mathrm{CsCl}$ can be added and the resulted glass is totally colorless [10]-[13].

However, the introduction of alkaline halides can affect the chemical durability of the glasses [10]. A compromise between an acceptable chemical durability and visible transmission must be found. To achieve the synthesis of composition with higher $\mathrm{CsCl}$ ratio and thus with better transparency in the visible, this work propose to study the impact of a protective coating. Considering the fact that all infrared optics will be protected by an antireflection coating containing generally $\mathrm{ZnS}$ [14], we have undertaken this study to investigate how a $\mathrm{ZnS}$ coating can protect the $\mathrm{GeS}_{2}-\mathrm{Ga}_{2} \mathrm{~S}_{3}-\mathrm{CsCl}$ glasses against external attack.

In this paper, our interest is focus on the potential of this system to establish some multispectral optics. Two stable compositions were chosen in the glassy domain allowing the preparation of glasses of large diameter. The optical properties, transmission and refractive index, will be described in order to find suitable composition transmitting in the whole visible range up to $11.5 \mu \mathrm{m}$. To go further, the molding ability and the protection against moisture are the last points investigated on these relevant compositions.

\section{Experimental}

\subsection{Glass preparation}

Bulk samples were prepared from high purity raw materials ( $\mathrm{Ge}, \mathrm{Ga}, \mathrm{S}$ and $\mathrm{CsCl}$ of $5 \mathrm{~N}$ ). Sulfur was purified by distillation under dynamic vacuum and stored with cesium chloride in a glove box under argon atmosphere. These compounds were weighed in stoichiometric proportions and introduced in a silica ampoule under vacuum $\left(10^{-4} \mathrm{~Pa}\right)$. The ampoule was placed in a rocking furnace during several hours at $850^{\circ} \mathrm{C}$ and quenched in water at room temperature. The sample was finally annealed near the glass transition temperature ( $\mathrm{Tg}$ ) for 4 hours to reduce mechanical stress induce during the quench. The rod of $25 \mathrm{~mm}$ or $45 \mathrm{~mm}$ diameter was then cut into slices of $2 \mathrm{~mm}$ thick or prism and thinly polished for different measurements.

\subsection{Samples characterizations}

The thermal analysis of the $20 \mathrm{Ga}_{2} \mathrm{~S}_{3}-65 \mathrm{GeS}_{2}-15 \mathrm{CsCl}$ sample was determined with a differential scanning calorimeter (DSC Q20 Thermal Analysis). A flat piece of glass in a sealed aluminum pan was heated following the three steps treatment describes below under nitrogen atmosphere. The characteristic temperatures were determined typically with a precision of about $+/-2^{\circ} \mathrm{C}$. Optical transmission was measured with a double beam spectrophotometer (Perkin Elmer Lambda 1050) in the visible and near IR ranges. A Brucker Tensor 37 spectrophotometer has been used for middle and far infrared transmission.

A radio-frequency (RF) magnetron sputtering system was used to deposit protective $\mathrm{ZnS}$ thin films on the 2 faces of the glasses. All samples were polished to a surface roughness of around $\mathrm{Ra}=10$ $\mathrm{nm}$ and were cleaned with ethanol, acetone and directly placed in the deposition chamber. The samples were kept at room temperature and the thin film deposition was performed under $20 \mathrm{sccm}$ Ar gas flow. The RF powers and the time were adjusted in order to obtain the same thickness in both face. The protective ability of the films was evaluated by measuring the optical transmission of the glass samples with and without coating. The molding ability of the two compositions has been performed with a Toshiba molding machine and the surface roughness was measured precisely with a Tallysurf equipment of Taylor Hobson.

The Littrow method has been used in order to measure the refractive index in the wavelength range of $2-10.7 \mu \mathrm{m}$ with a precision of $4.10^{-4}$. A prism of $30 \times 30 \mathrm{~mm}$ size with an angle of $22^{\circ}$ has been 
polished to measure the refractive index of one glass composition. For the other wavelengths $(633 \mathrm{~nm}$, $825 \mathrm{~nm}, 1061 \mathrm{~nm}, 1311 \mathrm{~nm}$ and $1511 \mathrm{~nm}$ ) the refractive index has been measured with a Metricon 2010/M Prism coupler. This measurement principle is commonly called M-line technique.

\section{Results and discussion:}

\subsection{Selected composition in $\mathrm{GeS}_{2}-\mathrm{Ga}_{2} \mathrm{~S}_{3}-\mathrm{CsCl}$ system}

The $\mathrm{Ga}_{2} \mathrm{~S}_{3}-\mathrm{GeS}_{2}-\mathrm{CsCl}$ system has been widely investigated from different point of view. The vitreous domain and the structure of these glasses has been determined by Tver'yanovich and al. [15], [16]. The role of the $\mathrm{CsCl}$ addition in $\mathrm{Ga}_{2} \mathrm{~S}_{3}-\mathrm{GeS}_{2}$ glassy matrix has also been highlighted before [12]. With the $\mathrm{CsCl}$ content augmentation, it induces a shift of the band-gap cutoff to lower wavelength and decreases the transition temperature. These glasses have a better stability against crystallization but the hygroscopic property of $\mathrm{CsCl}$ induces sensitivity to moisture. However, no further investigations were conducted on these glasses of high application potential.

To select a stable composition, the choice was realized among several compositions presenting a large difference between the transition temperature ( $\mathrm{Tg}$ ) and the crystallization temperature (Tx). As already done with the $15 \mathrm{Ga}_{2} \mathrm{~S}_{3}-75 \mathrm{GeS}_{2}-10 \mathrm{CsCl}$ composition [17], a specific thermal treatment monitored by DSC reveal the thermal dynamics of crystallization and complete this first criteria. The figure 1 shows the result in three steps for the $20 \mathrm{Ga}_{2} \mathrm{~S}_{3}-65 \mathrm{GeS}_{2}-15 \mathrm{CsCl}$ composition. The first treatment is a heating process at the rate of $10^{\circ} \mathrm{C} / \mathrm{min}$ until $\mathrm{Tx}+15^{\circ} \mathrm{C}$, then the sample is cooled down to $200^{\circ} \mathrm{C}$ and to finish, the last step heat the sample again until $\mathrm{Tx}+15^{\circ} \mathrm{C}$. The DSC curves are voluntarily offset for more clarity in the thermal event appreciation.

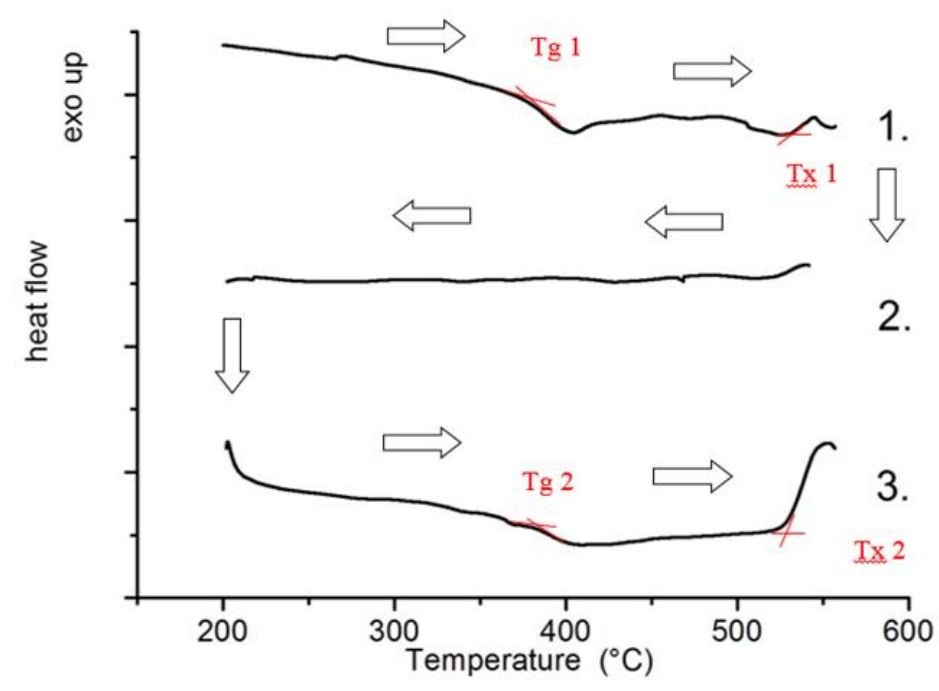

Figure 1: DSC analysis of $20 \mathrm{Ga}_{2} \mathrm{~S}_{3}-65 \mathrm{GeS}_{2}-15 \mathrm{CsCl}$

For this $20 \mathrm{Ga}_{2} \mathrm{~S}_{3}-65 \mathrm{GeS}_{2}-15 \mathrm{CsCl}$ composition, the first step shows a $\mathrm{Tg}_{1}$ at $378^{\circ} \mathrm{C}$ and a little crystallization peak at $\mathrm{Tx}_{1}=535^{\circ} \mathrm{C}$. The ramp to cool down the glass shows no particular thermal event. The second rise of the temperature shows again a $\mathrm{Tg}_{2}$ at $382^{\circ} \mathrm{C}$ and a bigger crystallization peak at $\mathrm{Tx}_{2}=$ $529^{\circ} \mathrm{C}$. This treatment highlights the stability of the glass and the low crystallization kinetics. The synthesis of a sample of $45 \mathrm{~mm}$ diameter was then realized (figure 2) without any crystallization confirming that our composition is stable. 


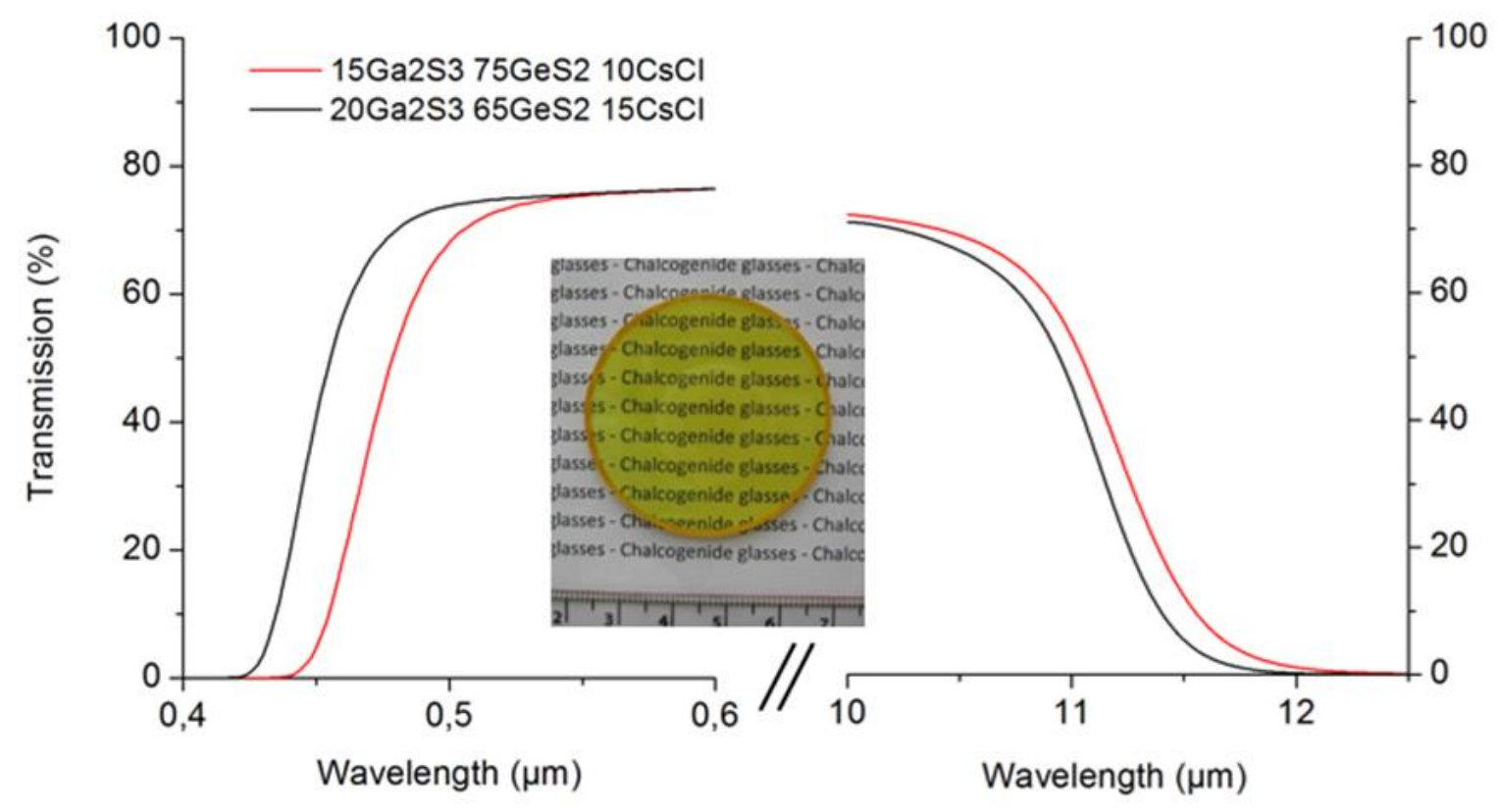

Figure 2: Comparison of $15 \mathrm{Ga}_{2} \mathrm{~S}_{3} 75 \mathrm{GeS}_{2} 10 \mathrm{CsCl}$ and $20 \mathrm{Ga}_{2} \mathrm{~S}_{3} 65 \mathrm{GeS}_{2} 15 \mathrm{CsCl}$ transmissions and a picture of the second composition with a $45 \mathrm{~mm}$ diameter

A comparison of the transmissions of these two glasses (showed in figure 2) has been done. In one hand, there is a shift in the visible transparency. Indeed, the visible transmission was improved with the $20 \mathrm{Ga}_{2} \mathrm{~S}_{3}-65 \mathrm{GeS}_{2}-15 \mathrm{CsCl}$ composition. In the other hand, in the infrared region this composition has a lower transparency than the $15 \mathrm{Ga}_{2} \mathrm{~S}_{3}-75 \mathrm{GeS}_{2}-10 \mathrm{CsCl}$ glass, the $\mathrm{Ga}_{2} \mathrm{~S}_{3} / \mathrm{GeS}_{2}$ and the increase of $\mathrm{CsCl}$ seems to generate these transmission effects. The ratio $\mathrm{Ga}_{2} \mathrm{~S}_{3} / \mathrm{GeS}_{2}$ has change between these two compositions from 0,31 to 0,20 for the $20 \mathrm{Ga}_{2} \mathrm{~S}_{3}-65 \mathrm{GeS}_{2}-15 \mathrm{CsCl}$ and $15 \mathrm{Ga}_{2} \mathrm{~S}_{3}-75 \mathrm{GeS}_{2}-10 \mathrm{CsCl}$ compositions respectively. According to the study of $\mathrm{Ga}_{2} \mathrm{~S}_{3}-\mathrm{GeS}_{2}$ system by X.F. Wang et $\mathrm{Al}$, the absorption edge in visible region increase first until 0.25 ratio and then decrease with increasing $\mathrm{Ga}_{2} \mathrm{~S}_{3} / \mathrm{GeS}_{2}$ ratio [18]. With our two values slightly above and under 0,25 the contribution of $\mathrm{Ga}_{2} \mathrm{~S}_{3} / \mathrm{GeS}_{2}$ ratio is not clearly highlight for these two compositions.

However, the growth of both $\mathrm{Ga}_{2} \mathrm{~S}_{3}$ and $\mathrm{CsCl}$ contents induces more formation of $\mathrm{GaS}_{4-\mathrm{x}} \mathrm{Cl}_{\mathrm{x}}$ tetrahedral dispersed in the glass network [19]. Due to this change of structure, the average number of $\mathrm{Ga}-\mathrm{S}$ bonds decreased to the benefit of $\mathrm{Ga}-\mathrm{Cl}$ bonds. According to previous results [12], the electronegativity of such bonds are 0.77 for $\mathrm{Ga}-\mathrm{S}$ and 1.35 for $\mathrm{Ga}-\mathrm{Cl}$. That explains the higher electronegativity of the glass when $\mathrm{CsCl}$ and $\mathrm{Ga}_{2} \mathrm{~S}_{3}$ higher proportions are added in the composition. This leads to a shift in the visible region to lower wavelength.

\subsection{Refractive index and chromatic dispersion}

The refractive indices of the glasses were measured with the Littrow method. To achieve this measurement, a prism of $30 \mathrm{~mm}$ as shown in figure 3 was cut into a $45 \mathrm{~mm}$ diameter glass rod. The prism was then polished and one face was recover with a thin gold layer to proceed to the measurements. 


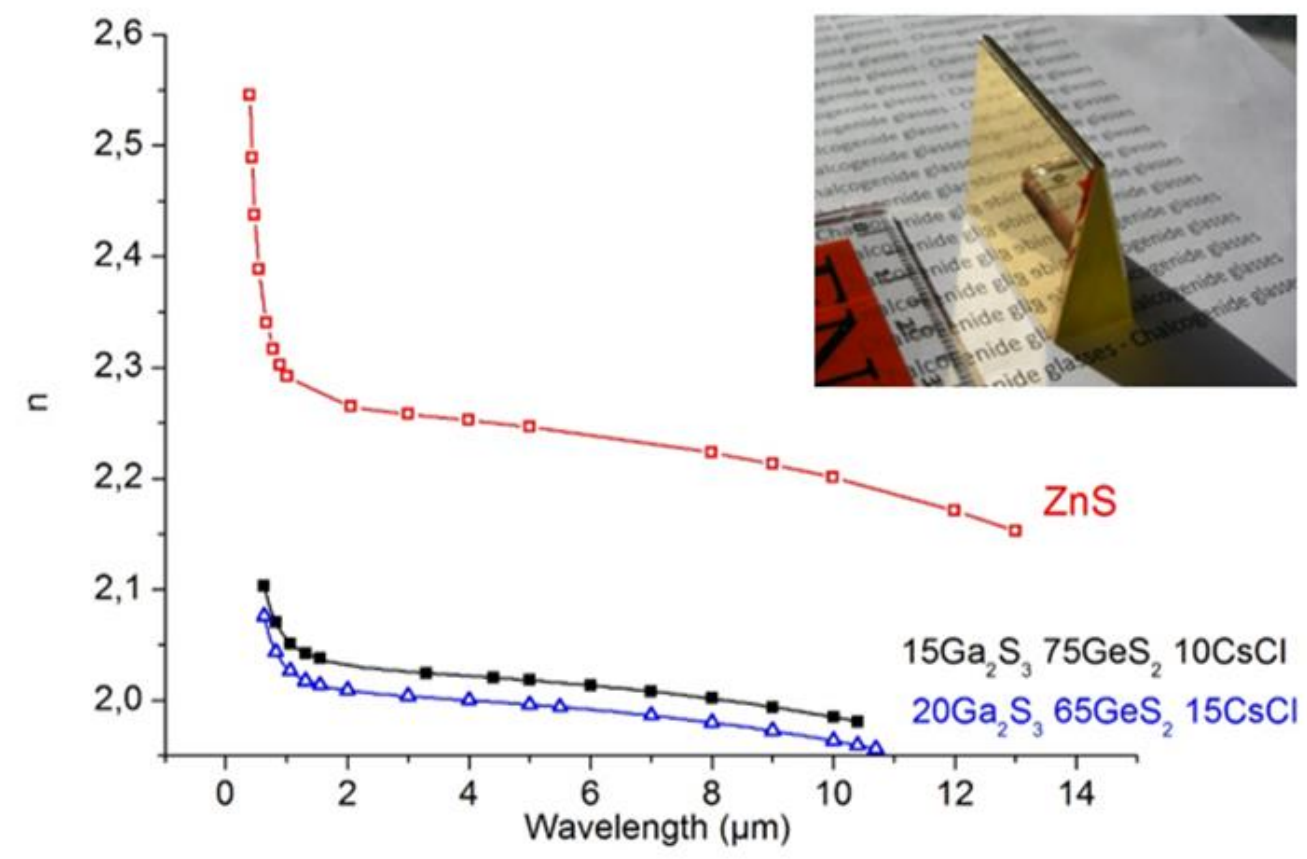

Figure 3: Refractive index of the two glasses compositions and $\mathrm{ZnS}$, the photograph shows the $20 \mathrm{Ga}_{2} \mathrm{~S}_{3}-65 \mathrm{GeS}_{2}-$ $15 \mathrm{CsCl}$ prism used for refractive index measurements

The Littrow method allows a precision of at least $4.10^{-4}$ for the measured refractive index. The chromatic dispersion can be thus calculated and compared with the $\mathrm{ZnS}[20]$ and the $15 \mathrm{Ga}_{2} \mathrm{~S}_{3}-75 \mathrm{GeS}_{2}-$ $10 \mathrm{CsCl}$ composition previously studied [17]. In the figure 3, the graphic presented the refractive index ranges of these three materials. The new composition $20 \mathrm{Ga}_{2} \mathrm{~S}_{3}-65 \mathrm{GeS}_{2}-15 \mathrm{CsCl}$ gave a glass with slightly lower refractive index compared with the other glass and strongly lower than the polycrystalline $\mathrm{ZnS}$.

Dispersion of these two different compositions was evaluated with the calculation of abbe numbers. These number are collected in the following table 1.

$$
V_{d}=\frac{n_{d}-1}{n_{F}-n_{C}}, V_{3-5}=\frac{n_{4}-1}{n_{3}-n_{5}} \text { and } V_{8-12}=\frac{n_{10}-1}{n_{8}-n_{12}}
$$

Where $V_{d}, V_{3-5}$ and $V_{8-12}$ are the Abbe numbers for the visible, 3-5 $\mu \mathrm{m}$ and 8-12 $\mu \mathrm{m}$ windows. In $V_{8-12}$ and $V_{3-5}$ formulas, $n_{x}$ is the refractive index at different wavelength in $\mu \mathrm{m}$. For $V_{d}$ calculation, $n_{\mathrm{d}}, n_{F}$ and $n_{C}$ are the refractive indices of the glasses at 587, 486 and $656 \mathrm{~nm}$, respectively.

Table 1: Abbe numbers of the two glass compositions and $\mathrm{ZnS}$ in the visible, and IR regions

\begin{tabular}{cccc}
\hline Composition & $V_{d}$ & $V_{3-5}$ & $V_{8-12}$ \\
\hline $20 \mathrm{Ga}_{2} \mathrm{~S}_{3}-65 \mathrm{GeS}_{2}-15 \mathrm{CsCl}$ & 15 & 128 & 24 \\
\hline $15 \mathrm{Ga}_{2} \mathrm{~S}_{3}-75 \mathrm{GeS}_{2}-10 \mathrm{CsCl}$ & 17 & 129 & 25 \\
\hline $\mathrm{ZnS} \mathrm{Cleartran}^{\circledR}$ & 16 & 113 & 23 \\
\hline
\end{tabular}

The three materials show similar values in the visible and $8-12 \mu \mathrm{m}$ infrared ranges. One interesting fact is the higher value of the two glasses in the $3-5 \mu \mathrm{m}$ near infrared image compared to $\mathrm{ZnS}$. This difference would provide a new possibility as optical lens material for multispectral imaging system. Indeed, to eliminate chromatic aberration, the combination of two lenses of different values of 
the dispersion is needed in a spectral band [21]. For the visible and $8-12 \mu \mathrm{m}$, the similar values reveal reduced choice to correct chromatic aberration in these bands for optical system.

\subsection{Protective coating deposition}

As previously mentioned, the halide addition in chalcogenide glasses has already been investigated to extend the transparency in the visible or increase the ionic conductivity [22], [23]. However, addition of alkali halide also induces a reduction of the chemical durability of the glasses.

Antireflective coatings already exist to improve the infrared transmission. Several solutions exist, a three layers coating based on $\mathrm{ZnSe}$ and $\mathrm{PbF}_{2}$ has been performed on $\mathrm{KCl}$ material by Atanassov and al. [24] or a double layer coating based on $\mathrm{ZnS}$ and $\mathrm{YbF} 3$ [14]. Considering the efficiency of $\mathrm{ZnS}$ coatings to prevent from corrosion this last treatment would be a good solution to combine both aspects (anticorrosion and antireflection).

RF magnetron sputtering is a commonly used technique for $\mathrm{ZnS}$ deposition [25]-[28]. In the figure 4 , the evolution of the transmission is shown for the $20 \mathrm{Ga}_{2} \mathrm{~S}_{3}-65 \mathrm{GeS}_{2}-15 \mathrm{CsCl}$ composition: an uncoated glass (left figure) and a glass with thin ZnS layer deposited by sputtering on the two faces (right figure). From an optical point of view, the atmosphere action on an uncoated chalcogenide glass will lead to the growth of hydroxyl and water absorption bands located respectively at $2.9 \mu \mathrm{m}$ and $6.3 \mu \mathrm{m}$. The surface defects created will lead to scatterings, hence decreasing the transmission threshold. A thin layer $(<1 \mu \mathrm{m})$ of $\mathrm{ZnS}$ has been applied on the two surfaces. The maximum transmittance and the absorption peaks depth remain unchanged (after 21 days), the evolution of the absorption bands is stopped. The thickness was calculated from optical measurement with a spectrophotometer. Using the envelope method [29], the two faces had a calculated thickness of $608 \mathrm{~nm}$ and $570 \mathrm{~nm}$ with a precision of $\pm 0,5 \mathrm{~nm}$.
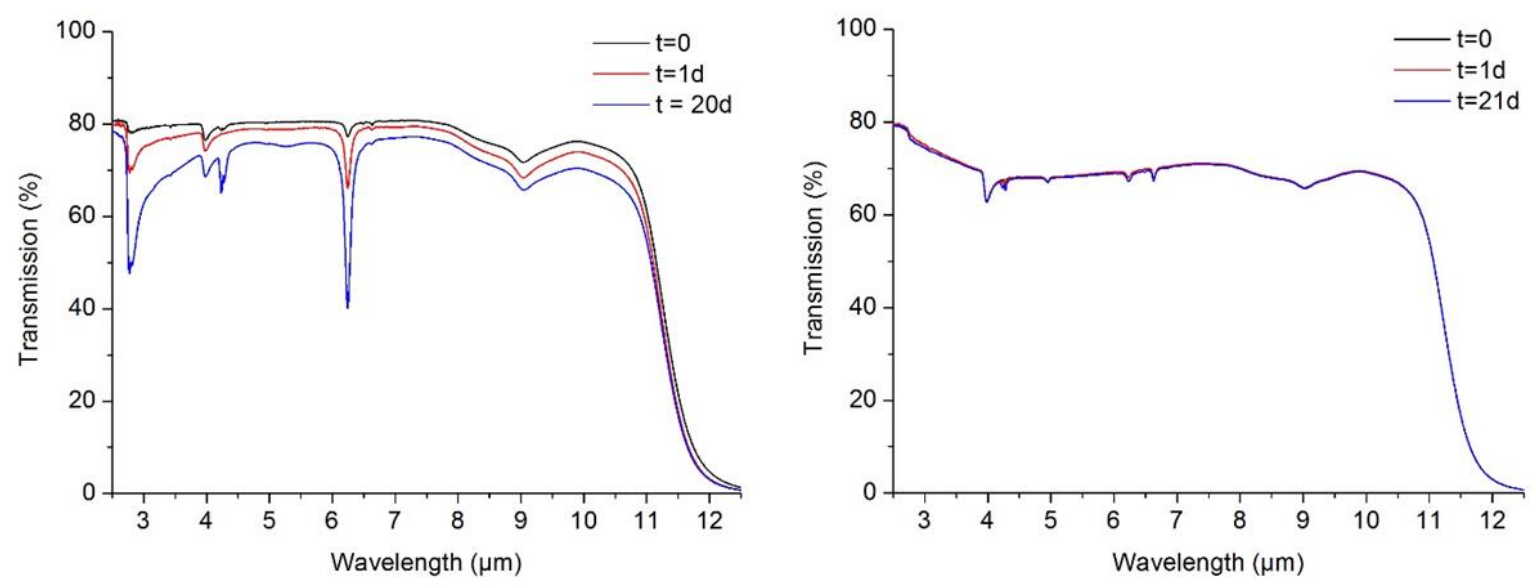

Figure 4: Evolution of the transmission of the uncoated glass $20 \mathrm{Ga}_{2} \mathrm{~S}_{3} 65 \mathrm{GeS}_{2} 10 \mathrm{CsCl}$ (left) and with a $\mathrm{ZnS}$ coating (right) after 1 day and 21 days

It is important to point out that the antireflection coating for the $8-12 \mu \mathrm{m}$ range has generally a thickness of several microns [14], much thicker than the 600nm tested in this study. Thus, the antireflection coating should provide an efficient protection against ambient moisture for these glasses. These results allow to consider in the future the synthesis of composition with higher $\mathrm{CsCl}$ ratio and thus more transparent in the visible.

\subsection{Molding tests}

Because of their viscoplastic properties glasses can be easily shaped under pressure at a temperature above $\mathrm{Tg}$ [4]. The two compositions highlighted previously can be synthesize in diameter 
of 25 and $50 \mathrm{~mm}$. The figure 5 demonstrates the feasibility to mold at $\mathrm{Tg}+100^{\circ} \mathrm{C}$ these two alkali-halide glasses under complex shape (aspheric on this example).

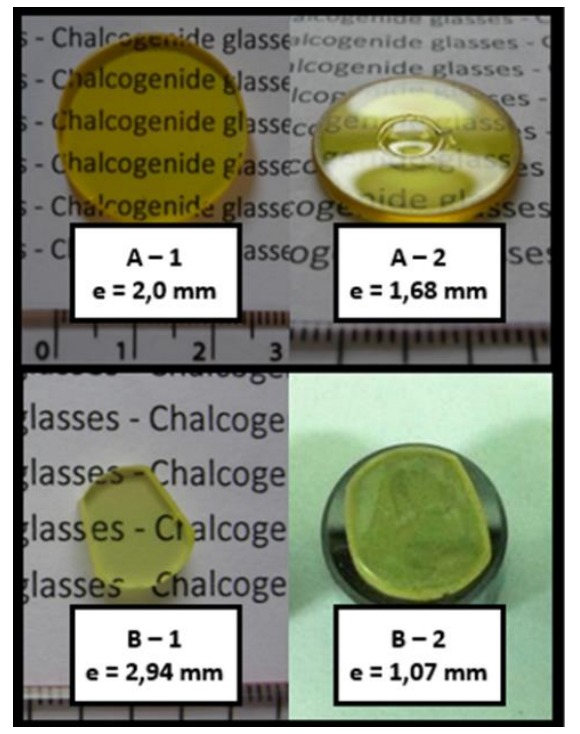

Figure 5: Molding of the compositions ${ }_{15 G a} \mathrm{~S}_{3}-75 \mathrm{GeS}_{2}-10 \mathrm{CsCl}$ (aspherical shape: A-1 and A-2) and 20Ga2 $\mathrm{S}_{3}-65 \mathrm{GeS}_{2}$ $15 \mathrm{CsCl}$ (flat shape: B-1 and B-2)

For the first composition $15 \mathrm{Ga}_{2} \mathrm{~S}_{3}-75 \mathrm{GeS}_{2}-10 \mathrm{CsCl}$, the picture A-2 shows the aspherical shape obtained by one step molding for a $25 \mathrm{~mm}$ diameter. The thickness decreases from $2 \mathrm{~mm}$ to $1.68 \mathrm{~mm}$. For the second composition $20 \mathrm{Ga}_{2} \mathrm{~S}_{3}-65 \mathrm{GeS}_{2}-15 \mathrm{CsCl}$, the molding was realized for a flat shape design. The pictures B-1 and B-2 present these samples with a thickness of $2.94 \mathrm{~mm}$ for the base glass and $1.07 \mathrm{~mm}$ after molding.

For both flat and aspherical shapes, no crystallization occurs during the molding process. The transmissions measured before and after the molding step for the $20 \mathrm{Ga}_{2} \mathrm{~S}_{3}-65 \mathrm{GeS}_{2}-15 \mathrm{CsCl}$ composition is presented in figure 6 . The increase of absorption band after the molding process can be explained by the delay between the synthesis and the molding operation (sample was stand in air). However, the transmission threshold remains unchanged at $80 \%$ of transmission.

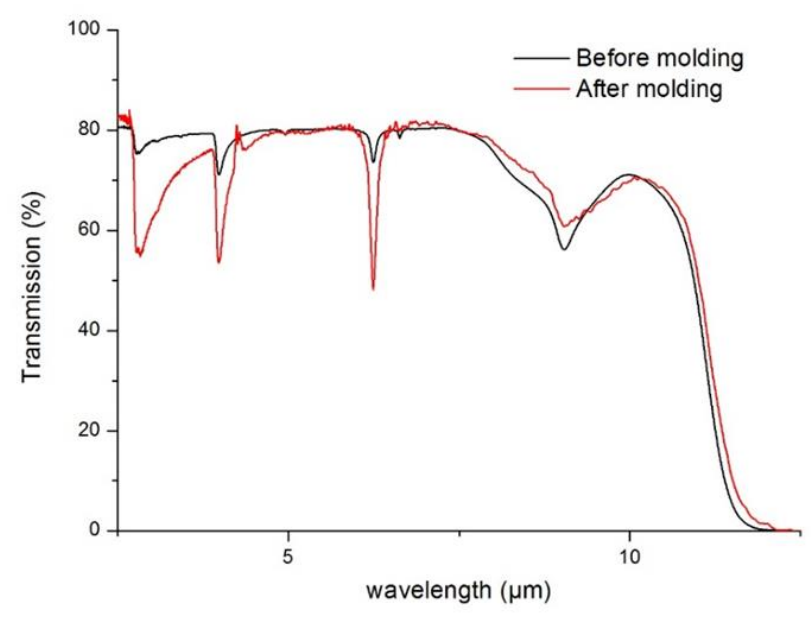

Figure 6: Transmission of the $20 \mathrm{Ga}_{2} \mathrm{~S}_{3}{ }_{65 \mathrm{GeS}} 15 \mathrm{CsCl}$ before and after molding

The roughness of the glass before and after the molding step was measured for the aspherical glass. A value of $\mathrm{Ra}=1.63 \mathrm{~nm}$ and $\mathrm{Ra}=4.6 \mathrm{~nm}$ for the initial glass and molded glass respectively was measured. The profile showed in the figure 7 exhibits the roughness Ra of the molded glass. Considering the roughness of the initial glass, the Ra increase due to the metal mold surface that demonstrate a similar 
value of Ra. Nevertheless, this value attests a good shaping of the material and its ability to form complex optics with a single molding.

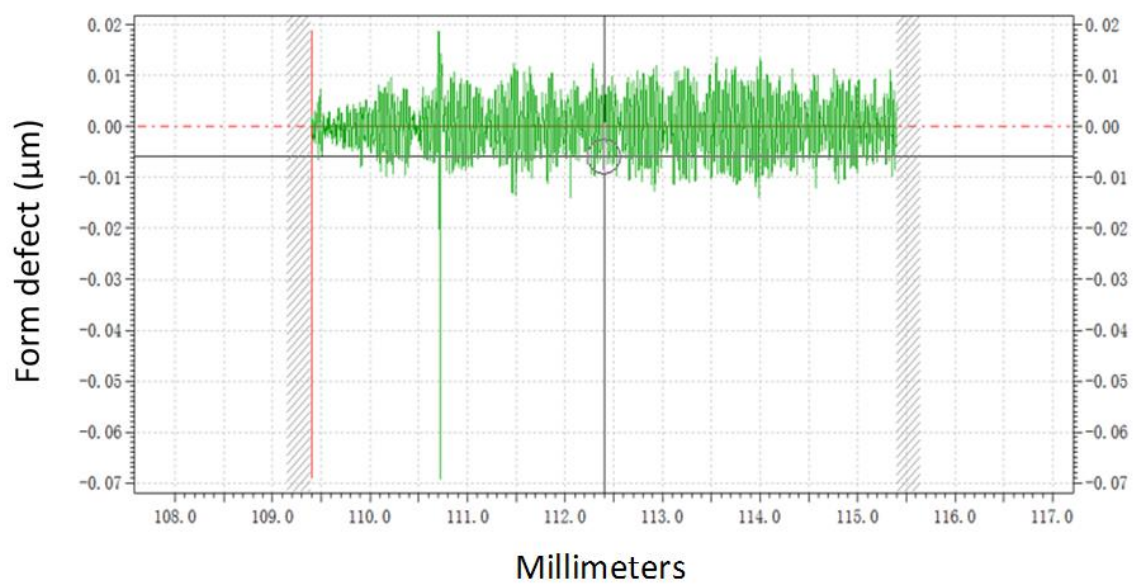

Figure 7: Control of the roughness of the aspherical shape

\section{Conclusions}

In this study, two chalcogenide glasses for multispectral imaging, especially visible and thermal imaging, have been developed and characterized. After a confirmation of their great thermal stability against the crystallisation, different optical properties were studied in detail. These glasses are transparent from 0.5 to $11 \mu \mathrm{m}$ and thus cover a huge spectral band. The refractive indices were precisely measured in this particular range in order to study the chromatic dispersion particularly in the three windows of high interest (visible, SWIR and Thermal infrared). It is interesting to notice that these glasses are less dispersive than the $\mathrm{ZnS}$ in the SWIR band, offering a much more economic alternative of materials for optical designer. To evaluate the possibilty of protecting these glasses against moisture with an antiflecting coating, a $\mathrm{ZnS}$ layer has been deposited by sputtering on both surfaces of the samples. The measurement of the absorption bands due to water indicates that an efficient protection can be achieved with a coating of less than $1 \mu \mathrm{m}$. The molding ability was also successfully demonstrated on complex aspheric surfaces without any crystallization and with an excellent quality of molded surfaces.

\section{Acknowledgements}

This work has been supported by the French Direction Générale de l'Armement and the industrial partner THALES ANGENIEUX through the program ANR-12-ASTR-0016.

\section{References}

[1] A. Krier and Y. Mao, "High performance uncooled InAsSbP_InGaAs photodiodes for the 1.8$3.4 \mu \mathrm{m}$ wavelength range," Infrared Phys. Technol., no. 38, pp. 397-403, 1997.

[2] W. E. Tennant, S. Cabelli, and K. Spariosu, "Prospects of uncooled HgCdTe detector technology," J. Electron. Mater., vol. 28, no. 6, pp. 582-588, 1999.

[3] A. Rogalski, "Recent progress in infrared detector technologies," Infrared Phys. Technol., vol. 54, no. 3, pp. 136-154, May 2011.

[4] X. H. Zhang, Y. Guimond, and Y. Bellec, "Production of complex chalcogenide glass optics by molding for thermal imaging," J. Non-Cryst. Solids, vol. 326-327, pp. 519-523, Oct. 2003.

[5] M. Hubert, G. Delaizir, J. Monnier, C. Godart, H.-L. Ma, X.-H. Zhang, and L. Calvez, "An innovative approach to develop highly performant chalcogenide glasses and glass-ceramics transparent in the infrared range," Opt. Express, vol. 19, no. 23, pp. 23513-23522, 2011. 
[6] M. Rozé, L. Calvez, M. Hubert, P. Toupin, B. Bureau, C. Boussard-Plédel, and X.-H. Zhang, "Molded Glass-Ceramics for Infrared Applications: Molded Glass-Ceramics for Infrared Applications," Int. J. Appl. Glass Sci., vol. 2, no. 2, pp. 129-136, Jun. 2011.

[7] G. Wang, Q. Nie, X. Wang, S. Dai, T. Xu, X. Shen, and X. Zhang, "Research on the novel GeSe2-In2Se3-KBr chalcohalide optic glasses," Mater. Res. Bull., vol. 45, no. 9, pp. 11411144, Sep. 2010.

[8] G. Wang, Q. Nie, X. Wang, X. Shen, F. Chen, T. Xu, S. Dai, and X. Zhang, "New far-infrared transmitting Te-based chalcogenide glasses," J. Appl. Phys., vol. 110, no. 4, p. 043536, 2011.

[9] R. A. Paquin, Materials for Optical Systems. .

[10] Y. Ledemi, L. Calvez, M. Rozé, X.-H. Zhang, B. Bureau, M. Poulain, and Y. Messaddeq, "Totally visible transparent chloro - sulphide glasses based on Ga2S3 - GeS2 - CsCl," J. Optoelectron. Adv. Mater., vol. 9, no. 12, pp. 3751-3755, Dec. 2007.

[11] Y. Ledemi, B. Bureau, L. Calvez, M. Rozé, E. Guillevic, N. Audebrand, M. Poulain, Y. Messaddeq, and X.-H. Zhang, "Innovating transparent glass ceramics based on Ga2S3 - GeS2 CsCl," Optoeclectronics Adv. Mater. - Rapid Commun., vol. 3, no. 9, pp. 899-903, Sep. 2009.

[12] P. Masselin, D. Coq, L. Calvez, E. Petracovschi, E. Lépine, E. Bychkov, and X. Zhang, "CsCl effect on the optical properties of the 80GeS2-20Ga2S3 base glass," Appl. Phys. A, vol. 106, no. 3, pp. 697-702, Mar. 2012.

[13] Y. Ledemi, B. Bureau, L. Calvez, M. L. Floch, M. Rozé, C. Lin, X. H. Zhang, M. Allix, G. Matzen, and Y. Messaddeq, "Structural Investigations of Glass Ceramics in the $\mathrm{Ga}_{2} \mathrm{~S}_{3}-\mathrm{GeS}_{2}$ -CsCl System,” J. Phys. Chem. B, vol. 113, no. 44, pp. 14574-14580, Nov. 2009.

[14] W. Liu, H. Tu, M. Gao, X. Su, S. Zhang, C. Huo, and H. Yang, "High performance DLC/BP and $\mathrm{ZnS} / \mathrm{YbF} 3$ double-layer protective and antireflective coatings," J. Alloys Compd., vol. 581, pp. 526-529, Dec. 2013.

[15] Y. S. Tver'yanovich, M. Vlček, and A. Tverjanovich, "Formation of complex structural units and structure of some chalco-halide glasses," J. Non-Cryst. Solids, vol. 333, no. 1, pp. 85-89, Jan. 2004.

[16] Y. S. Tver'Yanovich, V. V. Aleksandrov, I. V. Murin, and E. G. Nedoshovenko, "Glass-forming ability and cationic transport in gallium containing chalcohalide glasses," J. Non-Cryst. Solids, vol. 256, pp. 237-241, 1999.

[17] A. Brehault, L. Calvez, T. Pain, P. Adam, J. Rollin, and X. H. Zhang, "Multispectral glass transparent from visible to thermal infrared," in SPIE Defense+ Security, 2014, p. 90702F90702F.

[18] X. . Wang, X. . Zhao, Z. . Wang, H. . Guo, S. . Gu, J. . Yu, C. . Liu, and Q. . Gong, "Thermal and optical properties of GeS2-based chalcogenide glasses," Mater. Sci. Eng. B, vol. 110, no. 1, pp. 38-41, Jun. 2004.

[19] T. Haizheng, Z. Xiujian, J. Chengbin, Y. Hui, and M. Shun, "Raman scattering studies of the GeS2-Ga2S3-CsCl glassy system," Solid State Commun., vol. 133, no. 5, pp. 327-332, Feb. 2005.

[20] "Technical data sheet Zinc Sulfide Cleartran." [Online]. Available: www.ispoptics.com.

[21] A. Feltz, W. Burckhardt, B. Voigt, and D. Linke, "Optical glasses for IR transmittance," J. NonCryst. Solids, vol. 129, pp. 31-39, 1991.

[22] L. Calvez, P. Lucas, M. Rozé, H. L. Ma, J. Lucas, and X. H. Zhang, "Influence of gallium and alkali halide addition on the optical and thermo-mechanical properties of GeSe2-Ga2Se3 glass," Appl. Phys. A, vol. 89, no. 1, pp. 183-188, Aug. 2007.

[23] A. Bréhault, S. Cozic, R. Boidin, L. Calvez, E. Bychkov, P. Masselin, X. Zhang, and D. Le Coq, "Influence of $\mathrm{NaX}(\mathrm{X}=\mathrm{I}$ or $\mathrm{Cl})$ additions on $\mathrm{GeS} 2-\mathrm{Ga} 2 \mathrm{~S} 3$ based glasses," J. Solid State Chem., vol. 220, pp. 238-244, Dec. 2014.

[24] G. Atanassov, D. Popov, and P.-F. Gu, "Antireflection coatings on KCl single-crystal windows with low optical loss," Thin Solid Films, vol. 261, pp. 256-262, 1995.

[25] J. M. Blackmore and A. G. Cullis, "The structure of $\mathrm{ZnS}$ thin films deposited by r.f. sputtering," Thin Solid Films, vol. 199, pp. 312-334, Apr. 1991.

[26] L.-X. Shao, K.-H. Chang, and H.-L. Hwang, "Zinc sulfide thin films deposited by RF reactive sputtering for photovoltaic applications,” Appl. Surf. Sci., vol. 212-213, pp. 305-310, May 2003. 
[27] G. Kedawat, S. Srivastava, S. Sharma, Y. K. Vijay, P. Predeep, M. Thakur, and M. K. R. Varma, "Structural and Optical Properties of RF-Sputtered ZnS Thin Films," 2011, pp. 83-85.

[28] D. H. Hwang, J. H. Ahn, K. N. Hui, K. San Hui, and Y. G. Son, "Structural and optical properties of $\mathrm{ZnS}$ thin films deposited by RF magnetron sputtering," Nanoscale Res. Lett., vol. 7, no. 1, pp. 1-7, 2012.

[29] D. P. Arndt, R. M. A. Azzam, J. M. Bennett, J. P. Borgogno, C. K. Carniglia, W. E. Case, J. A. Dobrowolski, U. J. Gibson, T. Tuttle Hart, F. C. Ho, V. A. Hodgkin, W. P. Klapp, H. A. Macleod, E. Pelletier, M. K. Purvis, D. M. Quinn, D. H. Strome, R. Swenson, P. A. Temple, and T. F. Thonn, "Multiple determination of the optical constants of thin-film coating materials," Appl. Opt., vol. 23, no. 20, pp. 3571-3596, Oct. 1984. 